\title{
ANALISIS SECARA GC-MS SENYAWA AKTIF ANTIOKSIDAN FRAKSI N- HEKSANA DAUN LIBO (Ficus variegata Blume)
}

\author{
Vina Maulidya ${ }^{1,2, *}$ Myra Puspha Hardina ${ }^{1}$ Lizma Febrina ${ }^{1,2}$, Rolan Rusli ${ }^{1,2}$, \\ Agung Rahmadani ${ }^{1,2}$ \\ ${ }^{1}$ Laboratorium Penelitian dan Pengembangan Kefarmasian "Farmaka Tropis" \\ Fakultas Farmasi, Universitas Mulawarman, Samarinda, Indonesia \\ ${ }^{2}$ Kelompok Bidang Ilmu Kimia Farmasi, Fakultas Farmasi, Universitas Mulawarman, \\ Samarinda, Indonesia \\ *email: vina@farmasi.unmul.ac.id
}

\begin{abstract}
ABSTRAK
Tanaman Libo (Ficus variegata Blume) merupakan salah satu tumbuhan liar khas Kalimantan Timur sebagai sumber bahan larvasida dan antioksidan. Penelitian bertujuan untuk mengetahui komponen senyawa aktif antioksidan dalam fraksi $n$-heksana daun Libo dengan metode GC-MS. Interpretasi spektrum GC-MS dilakukan menggunakan database standar National Institute Standard and Technology (NIST). Komponen mayor fraksi n-heksana yang memiliki aktivitas antioksidan antara lain: cyclotetracosane; 1-heneicosanol; 1-docosene; 1,2-benzenedicarboxilic acid; 1-heptacosanol; octacosanol; dan cyclooctacosane.
\end{abstract}

Kata kunci: fraksi n-heksana daun Libo (Ficus variegata Blume.), antioksidan, GC-MS

https://doi.org/10.25026/jsk.v1i10.101

\section{PENDAHULUAN}

Tanaman Libo (Ficus variegata Blume) yang merukan salah satu tanaman liar khas Kalimantan Timur memiliki banyak aktivitas. Beberapa peneliti telah melaporkan aktivitas metabolit sekunder yang dimiliki oleh tanaman Libo (Ficus variegata Blume). Berbagai aktivitas metabolit sekunder baik pada ekstrak, fraksi, maupun isolat dari berbagai bagian tanaman (seperti daun, buah, dan kulit batang) yang telah dilaporkan oleh berbagai peneliti antara lain sebagai sitotoksik atau antikanker, pembasmi larva A. aegypti [1], sumber bahan antioksidan, dan sebagai antibakteri [1-9]. Karena kandungan metabolit sekunder Libo (Ficus variegata Blume) yang beraktivitas sebagai antioksidan, maka tanaman Libo (Ficus variegata Blume) dilaporkan berpotensi sebagai tabir surya [10] dan dapat dibuat menjadi sediaan antiseptik [11]. Tanaman Libo (Ficus variegata Blume) juga memiliki aktivitas sebagai obat penyembuh luka [12] dan antidiare [13] berdasarkan pengujian yang dilakukan pada hewan coba. Demikian banyaknya aktivitas yang dimiliki buah Libo (Ficus variegata Blume), namun laporan mengenai analisis GC-MS senyawa aktif antioksidan dari metabolit sekunder fraksi n-heksana belum pernah dilaporkan, sehingga dilakukan analisis senyawa aktif antioksidan fraksi 
n-heksana daun Libo (Ficus variegata Blume) secara GC-MS.

\section{METODE PENELITIAN}

Prosedur pengumpulan sampel, ekstraksi, hingga perolehan fraksi nheksana dari daun Libo (Ficus variegata Blume) yang memiliki aktivitas antioksidan adalah berdasarkan metode seperti yang telah dilaporkan oleh Rusli, dkk [2]. Fraksi aktif antioksidan n-heksana yang diperoleh dianalisis menggunakan Gas Chromatograpy-Mass Spectroscopy (GCMS) Shimadzu QP 5000. Sampel sebanyak $1 \mu \mathrm{L}$ diinjeksikan ke GC-MS yang dioperasikan menggunakan kolom kaca panjang $25 \mathrm{~m}$, diameter $0,25 \mathrm{~mm}$ dan ketebalan $0,25 \mu \mathrm{m}$ dengan fase diam $\mathrm{CP}$ Sil 5CB dengan temperatur oven diprogram antara $70-270{ }^{\circ} \mathrm{C}$ dengan laju kenaikan temperatur $10{ }^{\circ} \mathrm{C} /$ menit, gas pembawa helium bertekanan $12 \mathrm{kPa}$, total laju $30 \mathrm{~mL} / \mathrm{menit}$ dan split ratio sebesar 1:50.

\section{HASIL DAN PEMBAHASAN}

Kandungan golongan metabolit sekunder fraksi n-heksana daun Libo (Ficus variegata Blume) yang aktif sebagai antioksidan dapat dilihat pada Tabel 1 adalah berupa golongan alkaloid dan steroid/triterpenoid.

Spektrum GC-MS fraksi n-heksana daun Libo (Ficus variegata Blume) yang aktif sebagai antioksidan dapat dilihat pada Gambar 1. Identifikasi fraksi dilakukan dengan membandingkan pola fragmentasi spektrum massa dengan pola fragmentasi senyawa referensi yang berasal dari bank data WILLEY9THN 08.L, seperti dirangkum pada Tabel 2.

Tabel 1. Golongan metabolit sekunder fraksi n-heksana daun Libo (Ficus variegata Blume)

\begin{tabular}{cc} 
Pengujian Golongan Metabolit Sekunder & Hasil Pengujian \\
\hline Alkaloid & + \\
Flavonoid & - \\
Steroid/triterpenoid & + \\
Fenol & - \\
Saponin & - \\
\hline
\end{tabular}

Keterangan:

(+): Terdapat golongan metabolit sekunder yang diujikan

(-) : Tidak terdapat golongan metabolit sekunder yang diujikan

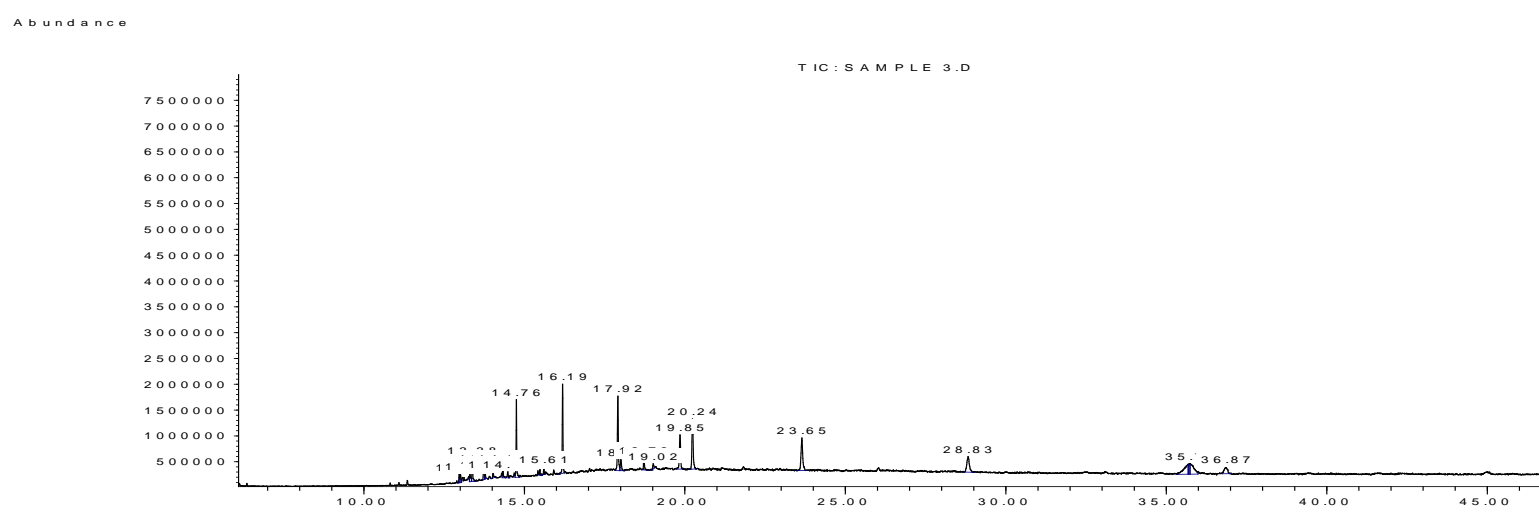

Gambar 1.Kromatogram GC-MS Fraksi Aktif Antioksidan n-Heksana Daun Libo (Ficus variegata Blume) 
Tabel 2. Hasil analisis GC-MS komponen kimia fraksi aktif Antioksidan n-Heksana Daun Libo (Ficus variegata Blume)

\begin{tabular}{|c|c|c|c|c|c|c|}
\hline Puncak & $\begin{array}{l}\text { Waktu } \\
\text { Retensi } \\
\text { (RT) }\end{array}$ & $\begin{array}{c}\% \\
\text { Area }\end{array}$ & Komponen Kimia & $\begin{array}{c}\text { Kemiripan } \\
(\%)\end{array}$ & $\begin{array}{l}\text { Rumus } \\
\text { Molekul }\end{array}$ & $\mathrm{BM}$ \\
\hline 1 & 13,31 & 1,43 & Nonylphenol & 83 & $\mathrm{C}_{15} \mathrm{H}_{24} \mathrm{O}$ & 220 \\
\hline 2 & 13,38 & 2,96 & Z-8-Hexadecene & 92 & $\mathrm{C}_{16} \mathrm{H}_{32}$ & 224 \\
\hline 3 & 13,73 & 1,71 & Neophytadiene & 98 & $\mathrm{C}_{20} \mathrm{H}_{38}$ & 278 \\
\hline 4 & 13,79 & 0,74 & (E)-3,13-Tetradecadien-2-one & 70 & & \\
\hline 5 & 14,48 & 0,93 & $\begin{array}{l}\text { 7,9-Di-tert-butyl-1-oxaspiro }(4,5) \text { d eca- } \\
\text { 6,9-diene-2,8-dione }\end{array}$ & 60 & $\mathrm{C}_{17} \mathrm{H}_{24} \mathrm{O}_{3}$ & 276 \\
\hline 6 & 14,75 & 8,20 & 1-Heneicosanol & 94 & $\mathrm{C}_{21} \mathrm{H}_{44} \mathrm{O}$ & 312 \\
\hline 7 & 16,20 & 10,43 & 1-Docosene & 99 & $\mathrm{C}_{22} \mathrm{H}_{44}$ & \\
\hline 8 & 17,91 & 11,23 & Cyclotetracosa-ne & 99 & $\mathrm{C}_{24} \mathrm{H}_{48}$ & 366 \\
\hline 9 & 18,02 & 2,08 & $\begin{array}{l}\text { Cyclohexaneca-rboxylic acid, dodecyl } \\
\text { ester }\end{array}$ & 70 & $\mathrm{C}_{19} \mathrm{H}_{36} \mathrm{O}_{2}$ & 296 \\
\hline 10 & 19,02 & 0,81 & Eicosane & 68 & $\mathrm{C}_{20} \mathrm{H}_{42}$ & 282 \\
\hline 11 & 19,85 & 6,90 & 1,2-Benzenedicar-boxylic acid & 87 & $\mathrm{C}_{8} \mathrm{H}_{6} \mathrm{O}_{4}$ & 166 \\
\hline 12 & 20,25 & 9,99 & 1-Heptacosanol & 94 & $\mathrm{C}_{27} \mathrm{H}_{56} \mathrm{O}$ & 396 \\
\hline 13 & 23,64 & 8,99 & Octacosanol & 95 & $\mathrm{C}_{28} \mathrm{H}_{58} \mathrm{O}$ & 410 \\
\hline 14 & 28,83 & 6,52 & Cyclooctacosa-ne & 96 & $\mathrm{C}_{28} \mathrm{H}_{56}$ & 392 \\
\hline 15 & 35,75 & 6,73 & $\begin{array}{l}\text { 7,8,17,18-Tetrahydro-35-methoxy-1, } \\
\text { 3,21,23-tetramethyl-16H,31H-5,9,15,19- } \\
\text { dime... }\end{array}$ & 53 & & \\
\hline 16 & 36,87 & 3,33 & 1,1,1,3,5,5,5-Heptamethyltrisiloxane & 41 & $\mathrm{C}_{7} \mathrm{H}_{22} \mathrm{O}_{2} \mathrm{Si}_{3}$ & 222 \\
\hline
\end{tabular}

Pada tabel 2 terlihat adanya beberapa komponen mayor dari senyawa pada fraksi n-heksana daun Libo (Ficus variegata Blume). Setiap komponen mayor merupakan komponen yang memiliki kuantitas terbanyak di dalam suatu fraksi sehingga beranggapan bahwa hasil identifikasi golongan metabolit sekunder dari fraksi isolat diduga dipengaruhi besar oleh adanya komponen mayor. Berdasarkan hasil GC-MS diketahui tidak ada satupun komponen mayor (Tabel 2) dari fraksi n-heksana yang tergolong ke dalam golongan metabolit sekunder baik alkaloid maupun steroid/triterpenoid (Tabel 1). Tetapi tidak menutup kemungkinan jika komponen minor dari tiap fraksi yang diduga dapat mempengaruhi hasil identifikasi golongan metabolit sekunder.
Pendekatan dilakukan dengan mencari senyawa yang memiliki kesamaan massa relatif (MR) dan kemiripan gambaran spektrum massa terhadap komponen mayor fraksi hasil analisis dengan GC-MS. Pencarian dilakukan dengan menggunakan aplikasi NIST MS Search 2.0.

Hasil pendekatan senyawa yang dilakukan dengan menggunakan aplikasi NIST MS Search 2.0. dapat dilihat pada tabel 3. Terdapat beberapa komponen mayor yang tidak memiliki hasil pendekatan senyawa. Hal ini diduga disebabkan oleh minimnya bank data dari aplikasi yang digunakan. Senyawasenyawa hasil pendekatan dari tiap komponen mayor kemudian diidentifikasi golongan metabolit sekundernya dengan cara melihat rumus strukturnya. Dilakukan 
penyesuaian antara rumus struktur dasar dari tiap golongan metabolit sekunder dengan struktur dari senyawa-senyawa hasil pendekatan. Dari seluruh hasil identifikasi maka hanya diperoleh senyawa hasil pendekatan yang tergolong sesuai dengan hasil identifikasi golongan metabolit sekunder fraksi n-heksana daun Libo (Ficus variegata Blume) yaitu senyawa 2-t-Butyl-3-methyl-4-oxo-5undecylimidazolidine-1-carboxylic acod, $t$ butyl ester yang merupakan senyawa hasil pendekatan senyawa komponen mayor octacosanol pada fraksi n-heksana.

Tabel 3. Hasil pendekatan komponen mayor dari fraksi n-heksana daun Libo (Ficus variegata Blume) menggunakan NIST MS Search

\begin{tabular}{|c|c|c|c|c|}
\hline \multirow{2}{*}{ Komponen Mayor } & \multirow{2}{*}{$\begin{array}{l}\text { Rumus } \\
\text { Kimia }\end{array}$} & \multirow{2}{*}{ MR } & \multicolumn{2}{|l|}{ Pendekatan Senyawa } \\
\hline & & & Nama Senyawa & Rumus Kimia \\
\hline Cyclotetrac-osane & $\mathrm{C}_{24} \mathrm{H}_{48}$ & 366 & - & - \\
\hline 1-Heneicosanol & $\mathrm{C}_{21} \mathrm{H}_{44} \mathrm{O}$ & 312 & $\begin{array}{c}\text { Oxalic acid, cyclohexylmethy-l nonyle } \\
\text { ester }\end{array}$ & $\mathrm{C}_{18} \mathrm{H}_{32} \mathrm{O}_{4}$ \\
\hline 1-Docosene & $\mathrm{C}_{22} \mathrm{H}_{44}$ & - & - & - \\
\hline $\begin{array}{l}\text { 1,2-Benzenedic- } \\
\text { arboxylic acid }\end{array}$ & $\mathrm{C}_{8} \mathrm{H}_{6} \mathrm{O}_{4}$ & 166 & - & - \\
\hline Octacosano-l & $\mathrm{C}_{28} \mathrm{H}_{58} \mathrm{O}$ & 410 & $\begin{array}{l}\text { 2-Benzhydrylideneamino-2-cyano-3- } \\
\text { phenylpropionic acid, t butyl ester } \\
\text { 2-t-Butyl-3-methyl-4-oxo-5- } \\
\text { undecylimidazol-idine-1-carboxylic } \\
\text { acod, t-butyl ester } \\
\text { Cyclohexanecarboxylic acid, 4-hexyl-, } \\
\text { 4-butoxy-2,3-dicyanophenyles-ter }\end{array}$ & $\begin{array}{l}\mathrm{C}_{27} \mathrm{H}_{26} \mathrm{~N}_{2} \mathrm{O}_{2} \\
\mathrm{C}_{24} \mathrm{H}_{46} \mathrm{~N}_{2} \mathrm{O}_{3}\end{array}$ \\
\hline 1-Heptacosan-ol & $\mathrm{C}_{27} \mathrm{H}_{56} \mathrm{O}$ & 396 & - & - \\
\hline Cyclooctaco-sane & $\mathrm{C}_{28} \mathrm{H}_{56}$ & 392 & $\begin{array}{c}\text { Benzene, 1,3,5-tris (2,2-dimethylpropyl)- } \\
\text { 2-methyl-4,6-dinitro- } \\
\text { 1-hexanol, (4S)-[(tert, butyloxycarbony- } \\
\text { l)-(S)-phenylalanylami-no]-2,3-epoxy-5- } \\
\text { methyl- } \\
\text { Butanoic acid, }(3 R S)-4-[(t- \\
\text { butoxycarbonyl- }(S)-\end{array}$ & $\begin{array}{l}\mathrm{C}_{22} \mathrm{H}_{36} \mathrm{~N}_{2} \mathrm{O}_{4} \\
\mathrm{C}_{21} \mathrm{H}_{32} \mathrm{~N}_{2} \mathrm{O}_{5}\end{array}$ \\
\hline
\end{tabular}

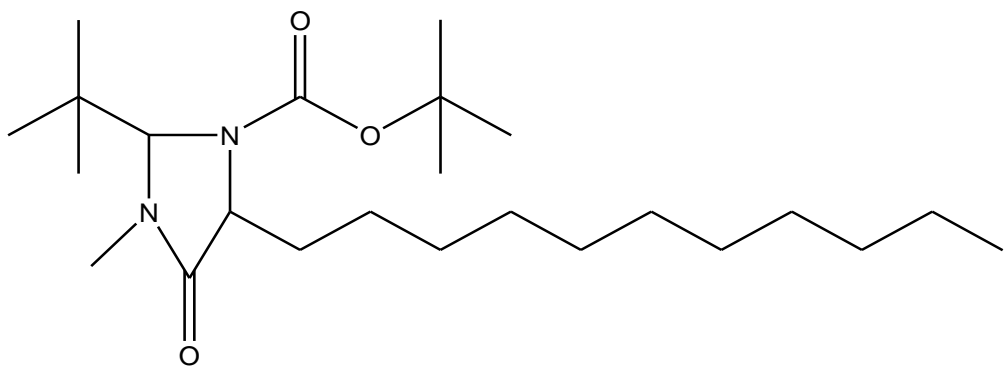

Gambar 2. Struktur kimia senyawa 2-t-Butyl-3-methyl-4-oxo-5-undecylimidazolidine-1carboxylic acod, t-butyl ester 
Senyawa tersebut memiliki kandungan nitrogen yang mana merupakan salah satu ciri dari alkaloid, yang strukturnya terlihat pada Gambar 2. Dengan adanya hal tersebut maka diduga hasil positif golongan metabolit sekunder alkaloid pada fraksi n-heksana diakibatkan adanya senyawa hasil pendekatan tersebut. Sedangkan untuk hasil positif golongan metabolit sekunder lainnya belum ditemukan senyawa yang mendekati atau memiliki kemiripan sehingga perlu dilakukan identifikasi lebih lanjut.

\section{KESIMPULAN}

Komponen Mayor yang diduga memiliki aktivitas antioksidan pada fraksi n-Heksan daun libo adalah 1-heptacosanol $(9,99 \%)$. antara lain cyclotetracosane; 1-heneicosanol; 1-docosene; 1,2-benzenedicarboxilic acid; 1heptacosanol; octacosanol; dan cyclooctacosane.

\section{DAFTAR PUSTAKA}

[1] Rijai, L., 2013. Potensi Tumbuhan Libo (Ficus variegata, Blume) sebagai Sumber Bahan Farmasi Potensial. J. Trop. Pharm. Chem. 2 (3). 166-179.

[2] Rusli, R., Hardina, M.P., Muflihah, F., Rahmadani, A., 2015. Profil Kromatografi Senyawa Aktif Antioksidan dan Antibakteri Fraksi NHeksana Daun Libo (Ficus variegata Blume). J. Trop. Pharm. Chem. 3 (2). 124-130

[3] Novitasari, M.R., Agustina, R., Rahmadani, A., Rusli, R., 2015. Profil Kromatografi Senyawa Aktif Antioksidan dan Antibakteri Fraksi Etil Asetat Daun Libo (Ficus variegata Blume. Jurnal Sains dan Kesehatan. 1 (3). 131-137.
[4] Novitasari, M.R., Febrina, L., Agustina, R., Rahmadani, A., Rusli, R., 2016. Analisis GC-MS Senyawa Aktif Antioksidan Fraksi Etil Asetat Daun Libo (Ficus variegata Blume.). Jurnal Sains dan Kesehatan. 1 (5). 221-225

[5] Nurtiwi, O.E., Rahmawati, D., Rusli, R., 2016. Aktivitas Antioksidan Fraksi N-Butanol Tanaman Libo (Ficus variegate Blume). Proceeding of Mulawarman Pharmaceuticals Conferences, $\mathbf{3}(2), \quad 318-321$. https://doi.org/10.25026/mpc.v3i2.127

[6] Saleh, R.A., Rahmadani, A., Febrina, L., Rusli, R., 2016. Aktivitas Antibakteri Kulit Batang Libo (Ficus variegate Blume). Proceeding of Mulawarman Pharmaceuticals Conferences, 3(2), 357-363. https://doi.org/10.25026/mpc.v3i2.133

[7] Utami, D.N., Rahmadhani, A., Fadraersada, J., Rusli, R., 2016. Aktivitas Antioksidan Kulit Batang Libo (Ficus variegata Blume). Proceeding of Mulawarman Pharmaceuticals Conferences, 3(2), 138-141.

https://doi.org/10.25026/mpc.v3i2.98.

[8] Cahyadi, D.D., Febrina, L., Rusli, R., 2016. Aktivitas Antioksidan Ekstrak Daun Libo (Ficus variegate Blume) dengan Berbagai Metode Ekstraksi. Proceeding of Mulawarman Pharmaceuticals Conferences, 3(2), 142-146.

https://doi.org/10.25026/mpc.v3i2.99.

[9] Ningsih, B.A., Rahmadani, A., Fadraersada, J., Rusli, R., 2016. Aktivitas Antibakteri dan Antioksidan Isolat Fraksi Etil Asetat Buah Libo (Ficus variegata Blume.). Proceeding of Mulawarman Pharmaceuticals Conferences, 3(2), 114-120. https://doi.org/10.25026/mpc.v3i2.95. 
[10] Aulia, I., Ayu, W.D., Rusli, R., 2016. Aktivitas Tabir Surya Fraksi NHeksana Buah Libo Berdasarkan Nilai SPF. Proceeding of Mulawarman Pharmaceuticals Conferences, 4(1), 154-161. https://doi.org/10.25026/mpc.v4i1.175

[11] Rusli, R., Ardana, M., Tambunan, S.M., 2018. Antiseptic Formulation of Libo Extract (Ficus varieagata Blume). International Journal of ChemTech Research.11 (05). 281284.
[12] Sugipratiwi, U., Maulidya, V., Rusli, R., 2016. Uji Aktivitas Antidiare Fraksi Etil Asetat Buah Libo (Ficus variegata Blume) pada Mencit (Mus musculus). Proceeding of Mulawarman Pharmaceuticals Conferences, 4(1), 372-376. https://doi.org/10.25026/mpc.v4i1.207

[13] Toding, M., Fridayanti, A., Ayu, W.D., Rusli, R., 2016. Pengaruh Pemberian Fraksi Etil Asetat Buah Libo (Ficus variegata B.) Terhadap Waktu Penyembuhan Luka Sayat pada Tikus Putih (Rattus norvegicus) Jantan Galur Wistar. Proceeding of Mulawarman Pharmaceuticals Conferences, $\mathbf{4}(1)$, 193-199. https://doi.org/10.25026/mpc.v4i1.181 